\title{
Doxycycline inhibits leukemic cell migration via inhibition of matrix metalloproteinases and phosphorylation of focal adhesion kinase
}

\author{
CHUNHUAI WANG ${ }^{1,2^{*}}$, RU XIANG $^{3 *}$, XIANGZHONG ZHANG $^{1}$ and YUNXIAN CHEN ${ }^{1}$ \\ ${ }^{1}$ Department of Hematology, The First Affiliated Hospital of Sun Yat-Sen University, Guangzhou, Guangdong 510080; \\ ${ }^{2}$ Department of Hematology, The Second Affiliated Hospital of Anhui Medical University; \\ ${ }^{3}$ Department of Internal Medicine, School of Nursing, Anhui Medical University, Hefei, Anhui 230601, P.R. China
}

Received July 3, 2014; Accepted March 16, 2015

DOI: $10.3892 / \mathrm{mmr} .2015 .3833$

\begin{abstract}
Doxycycline, a tetracycline-based antibiotic, has been reported to attenuate melanoma cell migration through inhibiting the focal adhesion kinase (FAK) signaling pathway. However, it remains to be elucidated whether doxycycline exerts this effect on leukemia cell migration. The present study aimed to examine the role of doxycycline in leukemia cell migration. The invasion capacities of the human leukemia cell lines KG1a (acute myelogenous leukemia) and K562 (chronic myelogenous leukemia) were evaluated using Matrigel ${ }^{\circledR}$ matrix-coated Transwell ${ }^{\circledR}$ chamber assays; leukemic cell lines treated with doxycycline $(1 \mu \mathrm{g} / \mathrm{ml})$ or anti- $\beta 1$-integrin antibodies were added to the upper chamber, while untreated cells were included as controls. Reverse transcription quantitative polymerase chain reaction was performed in order to further understand the influence of doxycycline treatment on the expression of FAK and gelatinases in the KG1a and K562 leukemic cell lines. In addition, FAK protein expression and phosphorylation were determined using western blot analysis in order to investigate the mechanism by which doxycycline inhibited leukemic cell migration. The results revealed that doxycycline treatment significantly attenuated the migration of KG1a and K562 cells, which was demonstrated to be associated with inhibition of the expression and phosphorylation of FAK. In addition, doxycycline treatment inhibited matrix metalloproteinase (MMP)-2 and MMP-9 expression. Furthermore, incubation with blocking anti- $\beta 1$-integrin antibodies had an analogous inhibitory effect on leukemic cell migration to that
\end{abstract}

Correspondence to: Dr Yunxian Chen, Department of Hematology, The First Affiliated Hospital of Sun Yat-Sen University, 15 Emerald Road, Guangzhou, Guangdong 510080, P.R. China E-mail: chenyxsci@163.com

*Contributed equally

Key words: doxycycline, leukemic cells, migration, focal adhesion kinase, gelatinases of doxycycline. In conclusion, the results of the present study suggested that doxycycline attenuated leukemic cell migration through inhibiting the FAK signaling pathway. Therefore, doxycycline may have potential for use as a novel strategy for the treatment of leukemia.

\section{Introduction}

The migration of cancer cells is a key step in tumor metastasis, which is associated with high mortality rates in cancer (1). The metastatic process involves the movement of cancer cells through the extracellular matrix (ECM) around the region of the primary tumor and requires adhesion of cancer cells to the ECM as well as ECM degradation (2). Focal adhesion kinase (FAK) and matrix metalloproteinases (MMPs) have been regarded as critical molecules in this process and previous studies indicated that the FAK pathway indirectly influences MMP activity as well as cell-ECM interactions (3-5).

Doxycycline, a member of the tetracycline group of antibiotics, is commonly used to treat a variety of infections (6). Numerous studies have demonstrated that doxycycline induced tumor apoptosis and suppressed tumor cell migration (7-9). Furthermore, the role of doxycycline as a non-specific MMP inhibitor has been established (10). Previous studies have demonstrated that doxycycline inhibited solid tumor metastasis via downregulation of FAK $(11,12)$. However, it remains to be elucidated whether doxycycline has an analogous effect on leukemia cells.

Acute myelogenous leukemia (AML) is a hematological malignancy, which may be regarded as a prototype of metastatic cancer. AML is characterized by the premature egress of leukemic blasts from the bone marrow and their dissemination into peripheral tissues (13). Increased gelatinase (MMP-2 and MMP-9) expression by AML blasts has been implicated in the invasive phenotype of AML (14). Expression of FAK in AML has been associated with enhanced blast migration, increased cellularity and poor prognosis (15).

The current study aimed to investigate the potential of doxycycline to attenuate the migration of leukemic cells through inhibiting leukemic cell expression of the gelatinases MMP-2 and MMP-9 via the FAK pathway. This study may 
therefore provide novel insights into the importance of doxycycline as a candidate for the treatment of leukemia patients.

\section{Materials and methods}

Chemical reagents. Doxycycline was purchased from Sigma-Aldrich (St. Louis, MO, USA). A stock solution was prepared at $10 \mathrm{mg} / \mathrm{ml}$ in phosphate buffered saline (PBS; Dingguo Biotech Corp., Guangzhou, China) and stored at $-20^{\circ} \mathrm{C}$

Cell culture. The human leukemia cell lines KG1a (acute myelogenous leukemia) and K562 (chronic myelogenous leukemia) were obtained from the Institute of Hematology and Hospital of Blood Diseases, Chinese Academy of Medical Sciences (Tianjin, China). Cells were cultured in RPMI 1640 medium (Gibco-BRL, Paisley, UK) supplemented with $10 \%$ fetal bovine serum (FBS; Gibco-BRL) and antibiotics (100 U/ml penicillin and $100 \mu \mathrm{g} / \mathrm{ml}$ streptomycin; Gibco-BRL). Cells were maintained at $37^{\circ} \mathrm{C}$ in humidified atmosphere containing $5 \% \mathrm{CO}_{2}$.

In vitro invasion assay. The invasion capacity of leukemic cells was evaluated using a Matrigel ${ }^{\circledR}$-coated Transwell ${ }^{\circledR}$ chamber system. RPMI 1640 medium (500 $\mu 1$ supplemented with 10\% FBS) containing $100 \mathrm{ng} / \mathrm{ml}$ stromal cell-derived factor- $1 \alpha$ (Wako Pure Chemical Industries, Ltd., Tokyo, Japan), a chemoattractant, was added to the lower chambers in the 24-well Transwell ${ }^{\circledR}$ plates (Corning, Inc., Corning, NY, USA). Membrane filters (Merck Millipore, Billerica, MA, USA; diameter, $6.5 \mathrm{~mm}$; pore size, $8 \mu \mathrm{m}$ ) were coated with $50 \mu \mathrm{g}$ Matrigel $^{\circledR}$ (BD Biosciences, San Jose, CA, USA), providing a composition similar to that of human basement membranes. Leukemic cell lines treated with doxycycline $(1 \mu \mathrm{g} / \mathrm{ml})$ or anti- $\beta 1$-integrin antibodies $(100 \mathrm{ng} / \mathrm{ml}$; Santa Cruz Biotechnology, Inc., Dallas, TX, USA,) were added to the upper chamber $\left(2.0 \times 10^{5}\right.$ cells/well in $200 \mu \mathrm{l}$ RPMI 1640), as previously described (16). Untreated cells were included as controls. Transwell ${ }^{\circledR}$ plates were incubated for $24 \mathrm{~h}$ at $37^{\circ} \mathrm{C}$ in a $\mathrm{CO}_{2}$ incubator. Subsequently, cells that had crossed the Matrigel ${ }^{\circledR}$ and migrated to the lower surface of the filter were fixed, stained with $0.1 \%$ crystal violet (Dingguo Biotech Corp.) and enumerated in ten randomly selected fields per filter under a light microscope (Olympus CKX41-A32RC inverted microscope; magnification, x200; Olympus Corp., Tokyo, Japan). The invasive cells on the lower surface of the membrane were stained by dipping inserts in the $0.1 \%$ crystal violet solution for $30 \mathrm{~min}$. The inserts were then rinsed in water and allowed to air dry. Each invasion experiment was performed in triplicate.

Reverse transcription quantitative polymerase chain reaction $(R T-q P C R)$. RT-qPCR was used to quantify messenger (m) RNA levels. KG-1a and K562 cells were treated with $1 \mu \mathrm{g} / \mathrm{ml}$ doxycycline (Sigma-Aldrich) or $100 \mathrm{ng} / \mathrm{ml}$ anti- $\beta 1$-integrin antibody (anti- $\beta 1$-integrin- $\mathrm{Ab}$ ) at $37^{\circ} \mathrm{C}$ in a $\mathrm{CO}_{2}$ incubator for $24 \mathrm{~h}$. A total of $1 \times 10^{6}$ cells were placed in $1.5 \mathrm{ml}$ tubes which were cooled on ice. Total RNA was extracted from cells using TRIzol ${ }^{\circledR}$ reagent (Invitrogen Life Technologies, Foster City, CA, USA) according to the manufacturer's instructions. A total of $4 \mu 1$ RNA was used to perform RT using an ABI 7500
Table I. Effects of doxycycline and anti- $\beta 1$ integrin- $\mathrm{Ab}$ on the invasiveness of KG1a and K562 human leukemia cell lines.

\begin{tabular}{lcc}
\hline & \multicolumn{2}{c}{ No. of migrated leukemia cells } \\
\cline { 2 - 3 } Group & KG1a & K562 \\
\hline Control & $25.00 \pm 3.91$ & $24.25 \pm 4.57$ \\
Doxycycline & $11.75 \pm 4.43^{\mathrm{a}}$ & $7.00 \pm 2.16^{\mathrm{a}}$ \\
Anti- $\beta 1$ integrin- $\mathrm{Ab}$ & $5.00 \pm 1.00^{\mathrm{a}}$ & $3.50 \pm 1.29^{\mathrm{a}}$ \\
\hline
\end{tabular}

Values are presented as the mean \pm standard deviation. ${ }^{a} \mathrm{P}<0.05$ vs. control group. Ab, antibodies.

Real-Time-PCR system (Applied Biosystems, Foster City, CA, USA) with the SYBR Green master mix (Applied Biosystems) and primers (Da'an Gene Co., Guangzhou, China). The sequences of the primers used for qPCR analysis were as follows: human MMP-2 forward, 5'-GGCCCCACAGGAGGA GAA-3' and reverse, 5'-GGTGCTGGCTGAGTAGATCCA-3'; human MMP-9 forward, 5'-AGATGCGTGGAGAGTCGA AATC-3' and reverse, 5'-GTCTCGGGCAGGGACAGTT-3'; human FAK forward, 5'-AGCAAGAAGAGCGCATGAGG-3' and reverse, 5'-GGGCGGTGCTTCATCAGA-3'; human $\beta$-actin forward, 5'-GCATGGGTCAGAAGGATTCCT-3' and reverse, 5'-TCGTCCCAGTTGGTGACGAT-3'. The reaction conditions were as follows: $93^{\circ} \mathrm{C}$ for $3 \mathrm{~min}$, followed by 40 cycles of $93^{\circ} \mathrm{C}$ for $30 \mathrm{sec}$ and $55^{\circ} \mathrm{C}$ for $45 \mathrm{sec} . \beta$-actin was used as a reference to obtain the relative fold change for targets using the comparative $\mathrm{Ct}$ method (17). All samples were analyzed in triplicate.

Western blotanalysis. In one treatment set, KG1a and K 562 cells were treated with doxycycline at 0.1 or $1 \mu \mathrm{g} / \mathrm{ml}$ for $1,3,6$ and $12 \mathrm{~h}$. In another treatment set, KGla and K562 cells were treated with $1 \mu \mathrm{g} / \mathrm{ml}$ doxycycline or $100 \mathrm{ng} / \mathrm{ml}$ anti- $\beta 1$-integrin-Ab for $24 \mathrm{~h}$ at $37^{\circ} \mathrm{C}$ in a $\mathrm{CO}_{2}$ incubator. Total protein was extracted from control leukemic cells and treated leukemic cells. Protein samples $(40 \mu \mathrm{g}$ ) were subjected to 10\% SDS-PAGE (Dingguo Biotech Corp) and transferred onto polyvinylidene difluoride membranes (Merck Millipore). Membranes were then blocked with 5\% skimmed milk in Tris-buffered saline with Tween 20 and reacted with the following primary antibodies: Anti-FAK (rabbit polyclonal; cat. no. 3283; 1:1,000 dilution), anti-p-FAK (Tyr576/577; rabbit polyclonal; cat. no. 3281; 1:1,000 dilution), anti-p-FAK (Tyr925; rabbit polyclonal; cat. no. 3284; 1:1,000 dilution), anti-MMP2 (rabbit polyclonal; cat. no. 4022; 1:1,000 dilution) and anti-MMP9 (rabbit polyclonal; cat. no. 2270; 1:1,000 dilution), which were purchased from Cell Signaling Technology (Danvers, MA, USA) as well as anti-p-FAK (Tyr397; rabbit monoclonal; cat. no. 44-625G; 1:1,000 dilution; Invitrogen Life Technologies). Following washing with PBS three times, membranes were incubated with goat anti-rabbit IgG, horseradish peroxidase-conjugated secondary antibody (Cell Signaling Technology, Danvers, MA, USA; cat. no. 7074; 1:1,000 dilution). Bands were visualized using enhanced chemiluminescence (SuperSignal West Pico chemiluminescent substrate; Pierce Biotechnology, Inc., Rockford, IL, USA). 

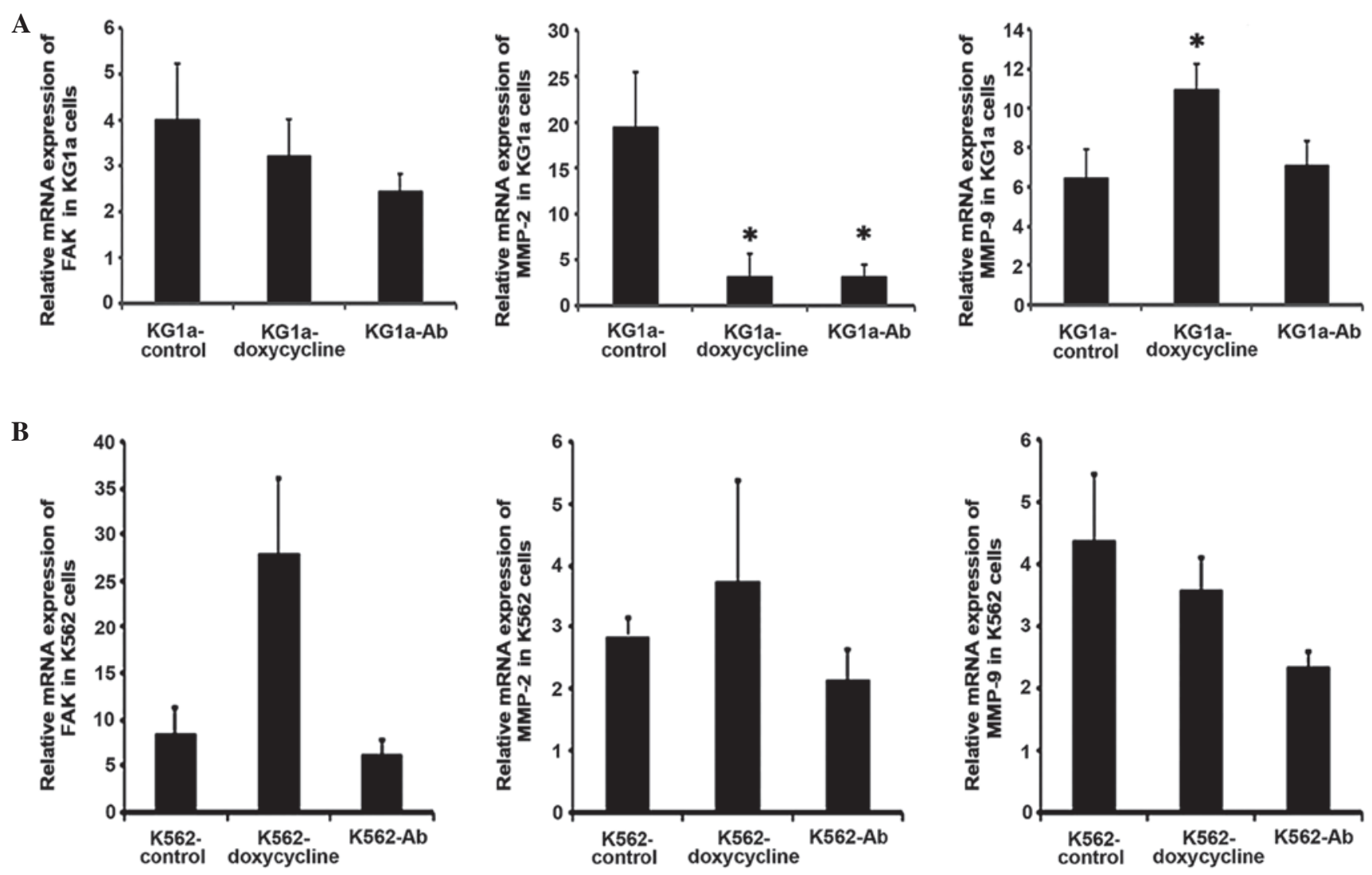

Figure 1. Effects of doxycycline or anti- $\beta 1$-integrin-Ab treatment on the transcription of FAK and gelatinases (MMP-2 and MMP-9) in KG1a cells and K562 human leukemia cells. mRNA levels of FAK, MMP-2 and MMP-9 were analyzed using reverse transcription quantitative polymerase chain reaction in (A) KG1a cells and (B) K562 cells following treatment with doxycycline $(1 \mu \mathrm{g} / \mathrm{ml})$ or anti- $\beta 1$-integrin-Ab (100 ng/ml). mRNA expression was quantified relative to that of $\beta$-actin. Values are presented as the mean \pm standard deviation of triplicate measurements. ${ }^{*} \mathrm{P}<0.05$ vs. control group. Ab, antibodies; FAK, focal adhesion kinase; MMP, matrix metalloproteinase; mRNA, messenger RNA.

GAPDH (rabbit monoclonal; cat. no. 5174; 1:1,000 dilution; Cell Signaling Technology) was used as internal control and was detected on the same membrane.

Statistical analysis. Values are expressed as the mean \pm standard deviation, unless otherwise stated. Statistical significance was evaluated using one-way analysis of variance tests with SPSS 11.0 software (SPSS, Inc., Chicago, IL, USA). P<0.05 was considered to indicate a statistically significant difference between values.

\section{Results}

Effect of doxycycline and anti- $\beta 1$-integrin on leukemic cell migration. The inhibitory effects of doxycycline and anti- $\beta 1$-integrin-Ab blocking treatment on the invasion capacity of KG1a and K562 cells were investigated using Matrigel ${ }^{\circledR}$ matrix-coated Transwell ${ }^{\circledR}$ chamber assays. As shown in Table I, doxycycline and anti- $\beta 1$-integrin-Ab were demonstrated to significantly decrease the number of migrated KG1a $(\mathrm{P}<0.001)$ and K562 $(\mathrm{P}<0.001)$ cells compared with that of the control group. This therefore indicated a marked reduction in the invasion capacity of these cells.

Transcription of FAK and gelatinases in leukemic cells following doxycycline or anti- $\beta 1$-integrin-Ab treatment. RT-qPCR was conducted in order to further understand the influence of doxycycline or anti- $\beta 1$-integrin-Ab treatment on the expression of FAK and gelatinases in the KGla and K562 leukemic cell lines (Fig. 1A and B).

As shown in Fig. 1A, in KGla cells, the levels of FAK mRNA were not significantly altered by doxycycline or anti- $\beta 1$-integrin-Ab treatment compared with those of untreated control cells. By contrast, MMP-2 mRNA expression was significantly decreased following treatment with doxycycline or anti- $\beta 1$-integrin-Ab compared with the control group $(\mathrm{P}<0.05)$. Furthermore, MMP-9 mRNA expression was significantly increased by doxycycline $(\mathrm{P}<0.05)$, whereas anti- $\beta 1$-integrin- $A b$ treatment exhibited no significant effect. As shown in Fig. 1B, no significant changes were detected in the levels of FAK, MMP-2 and MMP-9 mRNA in K562 cells following treatment with doxycycline or anti- $\beta 1$-integrin- $A b$.

Effects of different concentrations of doxycycline on FAK protein expression and phosphorylation. In order to investigate the mechanism by which doxycycline inhibited leukemic cell migration, FAK protein expression and phosphorylation were evaluated using western blot analysis. KG1a and K562 cells were treated with doxycycline at 0.1 or $1 \mu \mathrm{g} / \mathrm{ml}$ for $1,3,6$ and $12 \mathrm{~h}$. FAK is known to undergo adhesion-dependent phosphorylation on six tyrosine residues: $397,407,576,577,861$ and 925 (12); however, since neither the Tyr-407 or Tyr- 861 site has been reported to function in mediating interactions with effecter molecules, the functional significance of these 


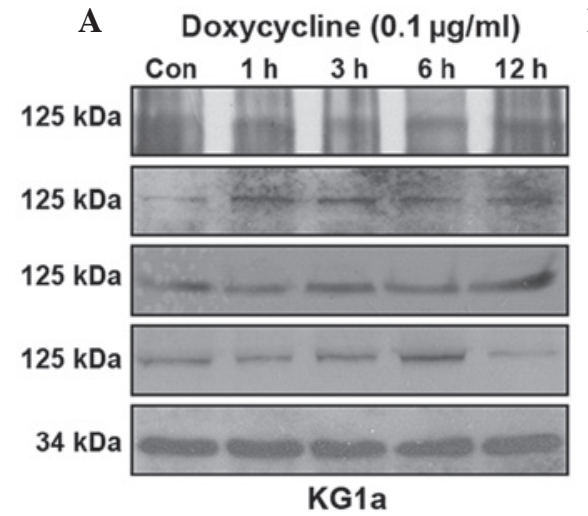

B Doxycycline $(1 \mu \mathrm{g} / \mathrm{ml})$

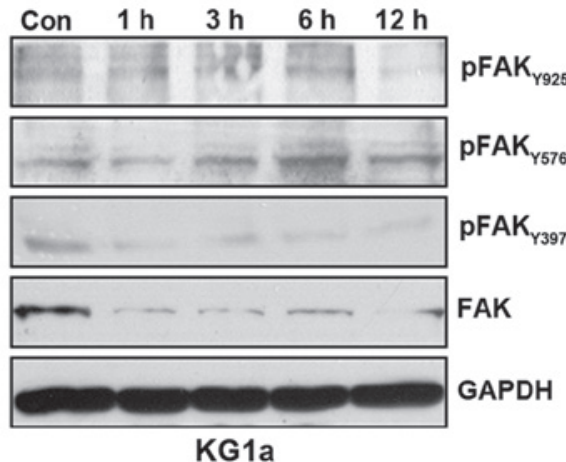

C Doxycycline $(0.1 \mu \mathrm{g} / \mathrm{ml})$

D Doxycycline $(1 \mu \mathrm{g} / \mathrm{ml})$
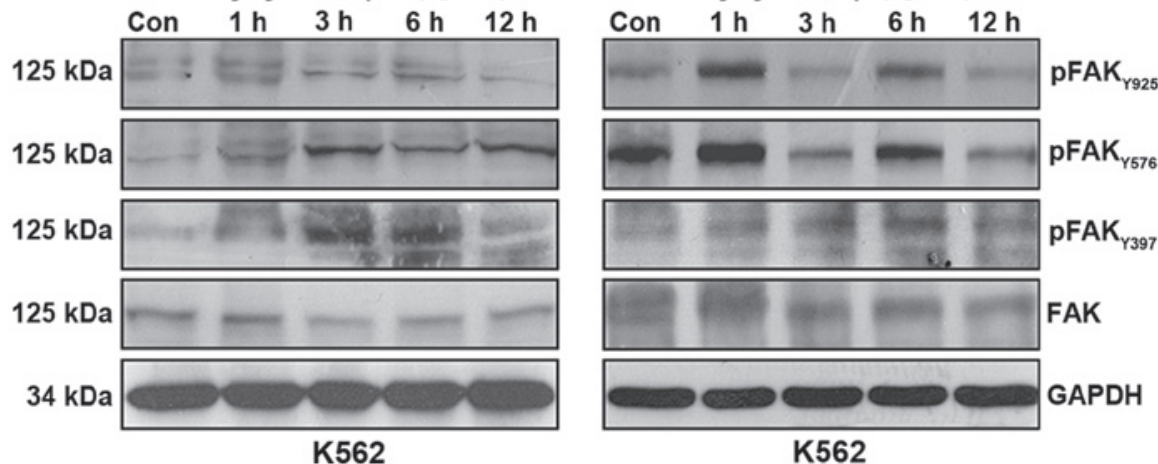

Figure 2. Dose- and time-dependent effects of doxycycline treatment on FAK protein expression and phosphorylation in KG1a and K562 leukemic cell lines. Levels of FAK protein and phosphorylated FAK at different sites (Y397, Y925 and Y576/577) were determined using western blot analysis following incubation with different doses of doxycycline for $1,3,6$ and $12 \mathrm{~h}$. (A) $0.1 \mu \mathrm{g} / \mathrm{ml}$ and (B) $1 \mu \mathrm{g} / \mathrm{ml}$ doxycycline treatment in KG1a cells. (C) $0.1 \mu \mathrm{g} / \mathrm{ml}$ and (D) $1 \mu \mathrm{g} / \mathrm{ml}$ doxycycline treatment in K562 cells. GAPDH was used as the loading control. FAK, focal adhesion kinase; Y, tyrosine; Con, control; p, phosphorylated.
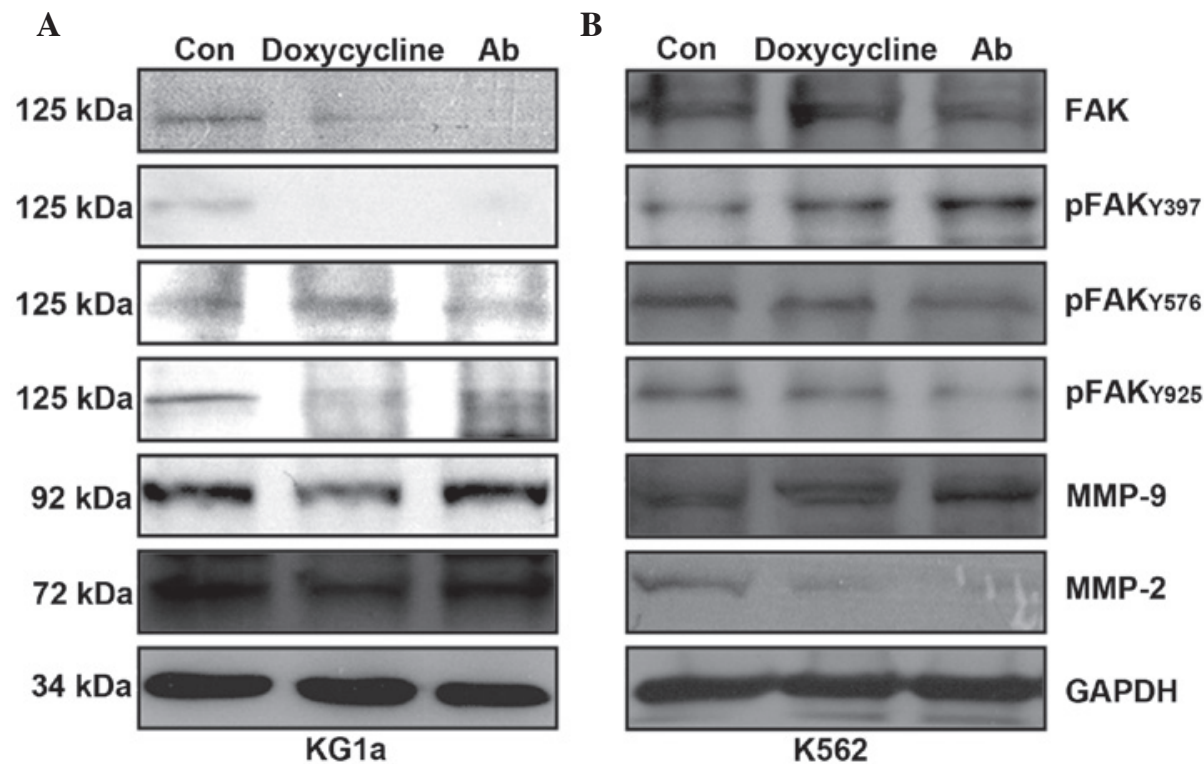

Figure 3. Effects of anti- $\beta 1$-integrin-Ab blocking treatment on FAK protein expression and phosphorylation as well as the expression of gelatinases (MMP-2 and MMP-9) in KG1a and K562 leukemic cell lines. Protein expression levels of FAK, pFAK at sites (Y397, Y925 and Y576/577), MMP-2 and MMP-9 were determined using western blot analysis in (A) KG1a and (B) K562 cells treated with doxycycline (1 $\mu \mathrm{g} / \mathrm{ml}) \mathrm{or}$ anti- $\beta 1$-integrin-Ab (100 ng/ml). GAPDH was used as the loading control. Ab, antibodies; FAK, focal adhesion kinase; MMP, matrix metalloproteinase; Y, tyrosine; Con, control; p, phosphorylated.

sites remains uncertain (18). Therefore, Tyr397, Tyr576/577 and Tyr 925 were analyzed in the present study.

The effects of doxycycline on FAK protein expression and phosphorylation were not consistent in the leukemic cells. Exposure of KGla cells to $0.1 \mu \mathrm{g} / \mathrm{ml}$ doxycycline decreased only the total protein expression of FAK and this effect was only apparent following $12 \mathrm{~h}$ of treatment (Fig. 2A). Of note, following treatment of KGla cells with $1 \mu \mathrm{g} / \mathrm{ml}$ doxycycline, decreased total FAK protein expression and Tyr397 phosphorylation were observed at $1 \mathrm{~h}$ post treatment; in addition, 
Tyr925 phosphorylation was inhibited following $12 \mathrm{~h}$ of treatment (Fig. 2B). Doxycycline treatment had no significant effects on Tyr576/566 phosphorylation at either dose (Fig. 2A and B).

By contrast, exposure of K 562 cells to $0.1 \mu \mathrm{g} / \mathrm{ml}$ doxycycline revealed a time-dependent decrease in Tyr925 phosphorylation (Fig. 2C). However, an increased concentration $(1 \mu \mathrm{g} / \mathrm{ml})$ of doxycycline exhibited no effect on total FAK expression and Tyr397 phosphorylation, although downregulation of Tyr576/577 and Tyr925 phosphorylation occurred following $12 \mathrm{~h}$ of treatment with $1 \mu \mathrm{g} / \mathrm{ml}$ doxycycline (Fig. 2D).

Expression of FAK, pFAK, gelatinases MMP-2 and MMP-9 following doxycycline or anti- $\beta 1$-integrin-Ab treatment. In order to investigate whether signaling downstream of the FAK pathway was involved in the doxycycline- or anti-31-integrin-Ab-mediated downregulation of gelatinases, KGla and K562 cells were treated with doxycycline $(1 \mu \mathrm{g} / \mathrm{ml})$ or anti- $\beta 1$-integrin- $\mathrm{Ab}(100 \mathrm{ng} / \mathrm{ml})$ for $24 \mathrm{~h}$. As shown in Fig. 3A, the expression of MMP-2, FAK, Tyr397-p-FAK and Tyr925-p-FAK were potently decreased by doxycycline and anti- $\beta 1$-integrin-Ab treatment in KGla cells. The anti- $\beta 1$-integrin-Ab also inhibited the expression of MMP-9 in KGla cells. As shown in Fig. 3B, both doxycycline and anti- $\beta 1$-integrin-Ab inhibited MMP-2, Tyr576/577-p-FAK and Tyr925-p-FAK in K562 cells, while FAK, Tyr397-p-FAK and MMP-9 were not impacted. However, exposure of K562 cells to identical conditions decreased only MMP-9 protein expression following doxycycline treatment (Fig. 3B).

\section{Discussion}

Tetracycline is a polyketide, which is produced by the Streptomyces genus of Actinobacteria and has been used as a broad-spectrum antibiotic for decades (19). Tetracycline functions as a protein synthesis inhibitor by binding to the $16 \mathrm{~S}$ ribosomal RNA portion of the $30 \mathrm{~S}$ ribosomal subunit and preventing amino-acyl transfer RNA from binding to the ribosome (20). Doxycycline, a member of the tetracycline group of antibiotics, has been reported to have a variety of antitumor effects in vitro (21), including impairment of mitochondrial protein synthesis $(22,23)$, proliferation arrest in the $G_{1}$ phase of the cell cycle (24) and induction of apoptosis via caspase-3 activation (8). The present study confirmed that doxycycline $(1 \mu \mathrm{g} / \mathrm{ml})$ exerted inhibitory effects on the proliferation of leukemia cells, with no significant cytotoxic effects detected using cell counting kit-8 assays in vitro (data not shown).

Studies have demonstrated that doxycycline exhibited direct weak cytotoxic and indirect inhibitory effects on tumor cell proliferation, angiogenesis, metastasis and migration through multiple targets $(11,25,26)$. However, the molecular mechanism of the antitumor effects of doxycycline remains to be fully elucidated. It was speculated that the interaction between tumor cells and ECM may be a critical stage in this process, leading to a series of consequential biological actions that control important tumor cell phenotypes $(27,28)$. The $F A K$ gene is ubiquitously expressed and encodes a non-receptor tyrosine kinase that localizes to focal adhesions on the cell membrane (29). FAK is a crucial signaling component activated by numerous stimuli, including growth factor receptors (epidermal and vascular endothelial growth factor receptors) and integrins, in order to regulate proliferation, survival and motility in normal cells as well as tumor cells (18). Breast cancer models have been employed to evaluate the role of FAK in regulating tumorigenic and metastatic properties (30). In addition, a study in human and mouse melanoma cell lines indicated that doxycycline inhibited adhesion and migration through downregulating the FAK signaling pathway (11). Furthermore, FAK signaling has been critically implicated in the generation of gelatinases and subsequent tumor invasion (31). However, it remained to be elucidated whether doxycycline exerts these effects on leukemia cells.

Acute leukemia is a hematopoietic malignancy that is widely circulated from its onset and may be regarded as a prototype of metastatic cancer (13). A previous study demonstrated that expression of FAK in leukemia was associated with enhanced blast migration and poor prognosis (16). Expression of gelatinases was also reported to have an essential role in the invasive capacity of AML and chronic myeloid leukemia, with emerging evidence suggesting that expression of these molecules may be mediated through the FAK/phosphoinositide 3-kinase (PI-3K)/extracellular signal-regulated kinase (ERK) signaling pathways $(16,32,33)$.

The present study investigated the effects of doxycycline on the invasiveness of two myelogenous leukemia cell lines, KGla and K562, as well as examined the role of the FAK signaling pathway and its influence on gelatinases in these effects. FAK is known to typically activate the migration of leukemic cells through the formation of integrin-dependent focal adhesions; in addition, $\beta 1$-integrin (CD29) has been reported to be expressed by the KG1a and K562 cell lines $(34,35)$. Therefore, it was hypothesized that treatment with a blocking anti- $\beta 1$-integrin-Ab may inhibit migration of leukemic cells at the levels of transcription, translation and phosphorylation. In the present study, KGla and K562 cells were treated with $100 \mathrm{ng} / \mathrm{ml}$ anti- $\beta 1$-integrin-Ab for $24 \mathrm{~h}$. As expected, the anti- $\beta 1$-integrin-Ab potently decreased migration of the leukemic cells in Matrigel ${ }^{\circledR}$ invasion assays. In addition, although mRNA levels of MMP-2 were significantly decreased in KG1a cells, MMP-9 mRNA levels were unchanged following treatment with anti- $\beta 1$-integrin- $\mathrm{Ab}$; these results were comparable to the effects of doxycycline. However, mRNA levels of MMP-2, MMP-9 and FAK remained stable in K562 cells following doxycycline or anti- $\beta 1$-integrin-Ab. Furthermore, at the protein level, the expression levels of FAK and MMP-2 as well as the phosphorylation of Tyr397 and Tyr925 were potently decreased by anti- $\beta 1$-integrin-Ab treatment of KGla cells. These results were comparable to the effects of doxycycline in KG1a. In K562 cells, anti- $\beta 1$-integrin-Ab treatment inhibited the expression of MMP-2 and phosphorylation of Tyr576 and Tyr925.

Cell migration is essential to tumor invasion and metastasis; therefore, the present study focused on the capacity of doxycycline to attenuate the migration of leukemic cells through inhibiting the FAK signaling pathway. FAK activation and degradation of the ECM have important roles in cell migration (36); therefore, it was hypothesized that doxycycline-mediated reduction of FAK and gelatinases may lead to decreased cell invasiveness. This hypothesis was tested in the present study using Matrigel ${ }^{\circledR}$ invasion assays, which demonstrated that exposure of KG1a and K562 leukemic 
cells to doxycycline decreased their invasive capacity. mRNA levels of FAK and the gelatinases (MMP-2 and MMP-9) were almost unchanged in K562 cells following doxycycline treatment; however, identical treatment of KG1a cells resulted in significantly decreased MMP-2 mRNA levels, while those of MMP-9 were increased. These data indicated that doxycycline exhibited no significant effect on FAK transcription in leukemic cells and demonstrated that the different leukemic cell lines had various sensitivities to doxycycline at the level of gelatinase transcription. These observations suggested that, paradoxically, transcription of FAK and gelatinases may not be essential for leukemic cell migration.

Phosphorylation, in particular tyrosine phosphorylation, is important for kinase activity and represents another mode of FAK regulation. FAK contains several tyrosine residues, including Tyr397, 407, 576, 577, 861 and 925, which are able to be phosphorylated (12). Tyr397 autophosphorylation is a key event in FAK activation, which results in the generation of a Src-homology-2 (SH2) binding site for Src (37). Following upstream activation of Src, the Tyr576/577 site of FAK is phosphorylated, which promotes maximal FAK catalytic activation (18). Src was also reported to phosphorylate the downstream effector FAK at Y407, 861 and 925. Phosphorylation of FAK by Src regulates its kinase activity and localization as well as its cellular motility and invasion (38). Of note, phosphorylation of the FAK C-terminal Tyr925 has been associated with Src-induced focal contact dynamics. In addition, phosphorylation of Tyr925 was reported to induce the generation of growth factor receptor-bound protein 2 (GRB2) binding site for GRB2, which activated the Ras-mitogen-activated protein kinase signaling cascade to promote focal contact turnover and contribute to cancer cell migration (39).

There is evidence to suggest that FAK-mediated signaling via Ras-related C3 botulinum toxin substrate 1 and Jun N-terminal kinases as well as FAK/PI-3K/ERK signaling may contribute to the expression of gelatinases and FAK-enhanced motility (40). Activation of MMPs is known to promote matrix proteolysis, leading to the extracellular release of integrin-matrix contacts, thereby facilitating focal contact remodeling and cell migration (41).

The present study demonstrated that the invasion ability of KG1a and K562 cells was inhibited by doxycycline; however, these results also indicated the existence of two different mechanisms underlying this effect in these leukemic cell lines. In KG1a cells, decreased expression of FAK following doxycycline treatment resulted in the inhibition of Tyr397 and Tyr925 phosphorylation, which subsequently led to downregulation of gelatinase expression, attenuation of focal contact turnover and blockade of ECM degradation. In K562 cells, doxycycline had no effect on expression of FAK and phosphorylation of Tyr397; however, doxycycline was able to downregulate Tyr576/577 and Tyr925 phosphorylation, ultimately leading to decreased focal contact remodeling and expression of MMP-2.

In the present study, analogous results to those of doxycycline were observed following treatment of KG1a and K562 cells with anti- $\beta 1$-integrin-Ab, which attenuated migration in these leukemic cells through inhibiting the expression and phosphorylation of FAK. These results suggested that doxycycline exerted its antimigratory effects through the FAK signaling pathway. In addition, a previous study demonstrated that dysfunction of $\beta 1$-integrin and FAK in K562 cells lead to abnormal adhesive characteristics (42). It was therefore proposed that disruption of aberrant $\beta 1$-integrin-mediated signaling by doxycycline restored normal adhesion mechanisms, which further indicated that the integrin-FAK signaling pathway may be a potential target of doxycycline.

In conclusion, the results of the present study demonstrated that doxycycline exerted a potent activity against the migration of leukemic cells in vitro. In addition to downregulation of FAK and its phosphorylation, the inhibition of downstream gelatinases was suggested to be involved in doxycycline-mediated inhibition of migration. These results therefore indicated the potential of doxycycline to attenuate the migration of leukemic cells through inhibiting the FAK signaling pathway.

\section{Acknowledgements}

The present study was supported by a grant from the Medical \& Health Technology Fund of Guangzhou City (grant no. 201102A212004).

\section{References}

1. Chiang AC and Massagué J: Molecular basis of metastasis. New Engl J Med 359: 2814-2823, 2008.

2. Friedl P and Alexander S: Cancer invasion and the microenvironment: Plasticity and reciprocity. Cell 147: 992-1009, 2011.

3. Nagase $\mathrm{H}$ and Woessner JF Jr: Matrix metalloproteinases. J Biol Chem 274: 21491-21494, 1999.

4. Egeblad M and Werb Z: New functions for the matrix metalloproteinases in cancer progression. Nat Rev Cancer 2: 161-174, 2002.

5. McLean GW, Carragher NO, Avizienyte E, Evans J, Brunton VG and Frame MC: The role of focal-adhesion kinase in cancer - a new therapeutic opportunity. Nat Rev Cancer 5: 505-515, 2005.

6. Rolain JM, Boulos A, Mallet MN and Raoult D: Correlation between ratio of serum doxycycline concentration to MIC and rapid decline of antibody levels during treatment of $\mathrm{Q}$ fever endocarditis. Antimicrob Agents Chemother 49: 2673-2676, 2005.

7. Fife RS, Sledge GW Jr, Sissons S and Zerler B: Effects of tetracyclines on angiogenesis in vitro. Cancer Lett 153: 75-78, 2000.

8. Iwasaki H, Inoue H, Mitsuke Y, Badran A, Ikegaya S and Ueda T: Doxycycline induces apoptosis by way of caspase-3 activation with inhibition of matrix metalloproteinase in human T-lymphoblastic leukemia CCRF-CEM cells. J Lab Clin Med 140: 382-386, 2002.

9. Fife RS, Sledge GW Jr, Roth BJ and Proctor C: Effects of doxycycline on human prostate cancer cells in vitro. Cancer Lett 127: 37-41, 1998.

10. Tu G, Xu W, Huang H and Li S: Progress in the development of matrix metalloproteinase inhibitors. Curr Med Chem 15: 1388-1395, 2008.

11. Sun T, Zhao N, Ni CS, et al: Doxycycline inhibits the adhesion and migration of melanoma cells by inhibiting the expression and phosphorylation of focal adhesion kinase (FAK). Cancer Lett 285: 141-150, 2009.

12. Mitra SK, Hanson DA and Schlaepfer DD: Focal adhesion kinase: in command and control of cell motility. Nat Rev Mol Cell Biol 6: 56-68, 2005.

13. Freireich EJ: Acute leukemia. A prototype of disseminated cancer. Cancer 53: 2026-2033, 1984.

14. Janowska-Wieczorek A, Marquez LA, Matsuzaki A, et al: Expression of matrix metalloproteinases (MMP-2 and -9) and tissue inhibitors of metalloproteinases (TIMP-1 and -2) in acute myelogenous leukaemia blasts: comparison with normal bone marrow cells. Br J Haematol 105: 402-411, 1999.

15. Recher C, Ysebaert L, Beyne-Rauzy O, et al: Expression of focal adhesion kinase in acute myeloid leukemia is associated with enhanced blast migration, increased cellularity and poor prognosis. Cancer Res 64: 3191-3197, 2004.

16. Berken A, Abel J and Unfried K: beta1-integrin mediates asbestos-induced phosphorylation of AKT and ERK1/2 in a rat pleural mesothelial cell line. Oncogene 22: 8524-8528, 2003. 
17. Ramakers C, Ruijter JM, Deprez RH and Moorman AF: Assumption-free analysis of quantitative real-time polymerase chain reaction (PCR) data. Neurosci Lett 339: 62-66, 2003.

18. Hanks SK, Ryzhova L, Shin NY and Brabek J: Focal adhesion kinase signaling activities and their implications in the control of cell survival and motility. Front Biosci 8: d982-996, 2003.

19. Adimora AA: Treatment of uncomplicated genital Chlamydia trachomatis infections in adults. Clin Infect Dis 35 (Suppl 2): S183-S186, 2002.

20. Olson MW, Ruzin A, Feyfant E, Rush TS III, O'Connell J and Bradford PA: Functional, biophysical and structural bases for antibacterial activity of tigecycline. Antimicrob Agents Chemother 50: 2156-2166, 2006.

21. Fife RS and Sledge GW Jr: Effects of doxycycline on in vitro growth, migration and gelatinase activity of breast carcinoma cells. J Lab Clin Med 125: 407-411, 1995.

22. Pilkington GJ, Parker K and Murray SA: Approaches to mitochondrially mediated cancer therapy. Semin Cancer Biol 18 : 226-235, 2008

23. Kroon AM, Dontje BH, Holtrop M and Van den Bogert C: The mitochondrial genetic system as a target for chemotherapy: tetracyclines as cytostatics. Cancer Lett 25: 33-40, 1984

24. van den Bogert C, van Kernebeek G, de Leij L and Kroon AM: Inhibition of mitochondrial protein synthesis leads to proliferation arrest in the G1-phase of the cell cycle. Cancer Lett 32: 41-51, 1986.

25. Sun B, Zhang S, Zhang D, et al: Doxycycline influences microcirculation patterns in B16 melanoma. Exp Biol Med (Maywood) 232: 1300-1307, 2007.

26. Saikali Z and Singh G: Doxycycline and other tetracyclines in the treatment of bone metastasis. Anti-cancer Drugs 14: 773-778, 2003

27. Gilmore AP, Owens TW, Foster FM and Lindsay J: How adhesion signals reach a mitochondrial conclusion-ECM regulation of apoptosis. Curr Opin Cell Biol 21: 654-661, 2009.

28. Sieg DJ, Hauck CR, Ilic D, et al: FAK integrates growth-factor and integrin signals to promote cell migration. Nat Cell Biol 2: 249-256, 2000

29. Golubovskaya VM and Cance W: Focal adhesion kinase and p53 signal transduction pathways in cancer. Front Biosci 15: 901-912, 2010.

30. Costa P, Scales TM, Ivaska J and Parsons M: Integrin-specific control of focal adhesion kinase and RhoA regulates membrane protrusion and invasion. PLoS One 8: e74659, 2013.

31. Duivenvoorden WC, Vukmirović-Popović S, Kalina M, Seidlitz E and Singh G: Effect of zoledronic acid on the doxycycline-induced decrease in tumour burden in a bone metastasis model of human breast cancer. Br J Cancer 96: 1526-1531, 2007.
32. Mon NN, Ito S, Senga T and Hamaguchi M: FAK signaling in neoplastic disorders: a linkage between inflammation and cancer. Ann N Y Acad Sci 1086: 199-212, 2006.

33. Dutta A, Sen T and Chatterjee A: Culture of K562 human myeloid leukemia cells in presence of fibronectin expresses and secretes MMP-9 in serum-free culture medium. Int J Clin Exp Pathol 3: 288-302, 2010.

34. Wang C, Chen Z, Li Z and Cen J: The essential roles of matrix metalloproteinase-2, membrane type 1 metalloproteinase and tissue inhibitor of metalloproteinase-2 in the invasive capacity of acute monocytic leukemia SHI-1 cells. Leuk Res 34: 1083-1090, 2010.

35. Liesveld JL, Winslow JM, Frediani KE, Ryan DH and Abboud $\mathrm{CN}$ : Expression of integrins and examination of their adhesive function in normal and leukemic hematopoietic cells. Blood 81: 112-121, 1993.

36. Guo-Bao W, Xiao-Qin C, Qi-Rong G, Jie L, Gui-Nan L and Yue L: Arsenic Trioxide overcomes cell adhesion-mediated drug resistance through down-regulating the expression of beta (1)-integrin in K562 chronic myelogenous leukemia cell line. Leuk Lymphoma 51: 1090-1097, 2010.

37. Cheng SY, Sun G, Schlaepfer DD and Pallen CJ: Grb2 promotes integrin-induced focal adhesion kinase (FAK) autophosphorylation and directs the phosphorylation of protein tyrosine phosphatase alpha by the Src-FAK kinase complex. Mol Cell Biol 34: 348-361, 2014.

38. Brunton VG, Avizienyte E, Fincham VJ, et al: Identification of Src-specific phosphorylation site on focal adhesion kinase: dissection of the role of $\mathrm{Src} \mathrm{SH} 2$ and catalytic functions and their consequences for tumor cell behavior. Cancer Res 65: 1335-1342, 2005.

39. Katz BZ, Romer L, Miyamoto S, et al: Targeting membrane-localized focal adhesion kinase to focal adhesions: roles of tyrosine phosphorylation and SRC family kinases. J Biol Chem 278: 29115-29120, 2003.

40. Li S, Butler P, Wang Y, et al: The role of the dynamics of focal adhesion kinase in the mechanotaxis of endothelial cells. Proc Natl Acad Sci USA 99: 3546-3551, 2002.

41. Brinckerhoff CE and Matrisian LM: Matrix metalloproteinases: a tail of a frog that became a prince. Nat Rev Mol Cell Biol 3: 207-214, 2002.

42. Lundell BI, McCarthy JB, Kovach NL and Verfaillie CM: Activation-dependent alpha5betal integrin-mediated adhesion to fibronectin decreases proliferation of chronic myelogenous leukemia progenitors and K562 cells. Blood 87: 2450-2458, 1996. 